\title{
ASTRONOMIA AGRÍCOLA EM ASPECTOS PRODUTIVOS E FISIOLÓGICOS DO RABANETE
}

\author{
Pedro Rodrigues Magalhães ${ }^{1}$, Hozano de Souza Lemos Neto ${ }^{2 *}$, Marcelo de Almeida \\ Guimarães $^{3}$, Bruno do Nascimento Silva ${ }^{4}$, Benedito Pereira Lima Neto ${ }^{4}$, Rosilene Oliveira \\ Mesquita $^{3}$

\footnotetext{
${ }^{1}$ Mestrando em Agronomia - Fitotecnia, Universidade Federal do Ceará, Fortaleza - CE.

${ }^{2}$ Doutorando em Agronomia - Fitotecnia, Universidade Federal do Ceará, Fortaleza - CE. E-mail: hozanoneto@hotmail.com

${ }^{3}$ Professor(a) do Departamento de Fitotecnia, CCA, Universidade Federal do Ceará, Fortaleza - CE.

${ }^{4}$ Graduando em Agronomia, Universidade Federal do Ceará, Fortaleza - CE.
}

RESUMO: O objetivo deste trabalho foi avaliar o desenvolvimento do rabanete em diferentes datas de semeadura estabelecidas de acordo com o Calendário AstronômicoAgrícola 2015. O experimento foi realizado na Horta Didática da Universidade Federal do Ceará, entre abril e junho de 2015. Utilizou-se o delineamento em blocos ao acaso, com quatro tratamentos (dias de 'raiz', 'folha', 'flor' e 'fruto') e cinco repetições. Avaliaram-se área foliar, número de folhas, massas fresca e seca da parte aérea e das túberas, comprimento e diâmetro das túberas, percentual de tuberização, clorofila ' $a$ ' e ' $b$ ', trocas gasosas e produção total. Foram observadas diferenças para número de folhas, área foliar, massa fresca e seca da parte aérea, clorofilas e trocas gasosas. O tratamento 'dia de folha' e 'fruto' foram os que proporcionaram maior concentração interna de $\mathrm{CO}_{2}$. Para a taxa fotossintética líquida e eficiência de carboxilação o 'dia de raiz' foi o que proporcionou plantas com os maiores valores. Para as características diâmetro, comprimento, massa fresca e seca das túberas, percentual de tuberização e produção total não foram observadas diferenças. Com base nos resultados, não se pode observar influência favorável desta distinção de dias de cultivo proposta pela agricultura biodinâmica na produção do rabanete.

Palavras-chave: Raphanus sativus L. Lua ascendente. Tuberização. Biodinâmica. Trocas gasosas.

\section{AGRICULTURAL ASTRONOMY'S IN PRODUCTIVE AND PHYSIOLOGICAL ASPECTS OF RADISH}

\begin{abstract}
The objective of this study was to evaluate the development of the radish on different dates of sowing established in accordance with the Astronomical CalendarAgricultural 2015. The experiment wasconducted in Kitchen Garden Teaching the Federal University of Ceará, between April and June 2015. We used the design in randomized blocks, with four treatments ('days root', 'leaf', 'flower' and 'fruit') and five repetitions. It was evaluated leaf area, number of leaves, fresh and dry weight of shoots and tubers, chlorophylls and gas exchange. There were significant differences for number of leaves, leaf
\end{abstract}

Cultura Agronômica, Ilha Solteira, v.26, n.3, p.375-383, 2017 
area, fresh and dry weight of shoot, chlorophyll and gas exchange. Being 'leaf day' and 'fruit' were provided greater internal $\mathrm{CO}_{2}$ concentration. To the net photosynthetic rate and carboxylation efficiency the 'root day' was the most favorable. For the characteristics diameter, length, fresh and dry weight of truffles, tuber percentage and total production differences were observed. Based on results can not clearly observe the influence of this culture system for the production of radish.

Key words: Raphanus sativus L. Ascending moon. Tuberization. Biodynamics. Gas exchange.

\section{INTRODUÇÃO}

O rabanete (Raphanus sativus L.) é considerado uma planta de ciclo curto, com duração aproximada de 30 dias. O fim do crescimento vegetativo da planta é o de maior armazenamento de nutrientes, juntamente com o desenvolvimento da raiz tuberosa, órgão de interesse comercial. Após isso, inicia-se a fase reprodutiva, fase na qual ocorre o florescimento e a frutificação, o que não interessa ao consumidor, pois há o endurecimento da raiz (PEREIRA, 2002).

A túbera possui forma, tamanho e cor variáveis com a cultivar (GUIMARÃES; FEITOSA, 2014). No entanto, as cultivares de mesa geralmente apresentam raízes arredondadas, casca vermelho-arroxeada e interior branco ou rosado (LIRA, 2013). O rabanete é considerado uma hortaliça nutracêutica por possuir propriedades medicinais como substâncias anticarcinogênicas. Além de possuir fibras, vitaminas e antioxidantes importantes para a saúde humana (MORAES; COLLA, 2006).

Atualmente, o principal sistema de cultivo é o convencional, no qual há elevada utilização de defensivos agrícolas e adubos minerais solúveis (BEVILACQUA, 2006). Sendo assim, são necessários o desenvolvimento, o estudo e a avaliação de sistemas de produção alternativos que possibilitem a menor utilização desses defensivos e adubos e que forneçam maior segurança à saúde dos trabalhadores e consumidores.

Dentro dos sistemas alternativos de cultivo, importante destaque tem sido feito à chamada Agricultura Biodinâmica. Essa forma de agricultura preconiza o autoconhecimento do ser humano e sua relação com o Universo, buscando a melhoria da relação entre o homem e o sistema de cultivo, baseando-se na influência dos astros, a fim de se obter uma produção sustentável (ORMOND et al., 2002). A Agricultura Biodinâmica é caracterizada por práticas semelhantes ao sistema de cultivo orgânico como a não utilização de adubos minerais, defensivos sintéticos, hormônios de crescimento e transgênicos, por exemplo (SIXEL, 2003).

A principal característica desse sistema produtivo é a utilização dos conhecimentos propostos pela Astronomia Agrícola para a escolha do período mais adequado à realização de cada atividade agrícola, de acordo com o calendário astronômico. Acredita-se que as 
plantas produzem substâncias que alteram seu ciclo de vida, sendo influenciadas pela posição da Terra frente às constelações e em consonância com a Lua, sendo capaz de alterar o desenvolvimento de cada órgão da planta (JOVCHELEVICH, 2007; SCHWENGBER et al., 2013; MENIN et al., 2014). Ou seja, a proposta é que haja dias favoráveis e desfavoráveis ao cultivo de raízes, folhas, flores e frutos (THUN, 1986; JOVCHELEVICH, 2007; SCHWENGBER et al., 2013; MENIN et al., 2014). Assim, objetivou-se avaliar o desempenho produtivo e fisiológico do rabanete em diferentes datas de semeadura de acordo com o Calendário Astronômico-Agrícola 2015 (THUN, 2015).

\section{MATERIAL E MÉTODOS}

O experimento foi realizado em área aberta, na Horta Didática do Departamento de Fitotecnia, Centro de Ciências Agrárias da Universidade Federal do Ceará, Fortaleza - CE, entre abril e junho de 2015. As coordenadas geográficas do local de cultivo são $3^{\circ} 44^{\prime} \mathrm{S}$ e $38^{\circ} 33^{`} \mathrm{~W}$ e altitude de $19,5 \mathrm{~m}$ aproximadamente. O clima do local segundo a classificação climática de Köppen, é do tipo Aw', ou seja, tropical chuvoso. As médias de temperaturas máxima e mínima durante a realização do trabalho foram de $30,5^{\circ} \mathrm{C}$ e $22,7^{\circ} \mathrm{C}$; precipitação média 7,1 mm; e umidade relativa de $78 \%$.

O delineamento experimental foi em blocos ao acaso, com quatro tratamentos e cinco repetições. Os tratamentos consistiram em diferentes datas de semeadura referentes ao período mais adequado à produção de diferentes órgãos das plantas (raiz, folha, flor e fruto), de acordo com o calendário Astronômico-Agrícola 2015 (THUN, 2015). A semeadura correspondente ao dia de folha foi realizada em 26 de abril (Lua em Câncer); a do dia de fruto 27 de abril (Lua em Leão); a do dia de raiz 30 de abril (Lua em Virgem); e a do dia de flor em 3 de maio (Lua em Libra). Considerou-se a fase crescente da Lua (MENIN et al., 2014).

Cerca de 15 dias antes da semeadura de cada tratamento procedeu-se a limpeza da área com capina manual; em seguida, revirou-se a camada subsuperficial do solo até a profundidade de 0,2 m, aproximadamente, e distribuiu-se de forma homogênea 200 litros de composto orgânico por canteiro $\left(10 \mathrm{~m}^{2}\right)$.

No dia da semeadura, foram incorporados mais 22 litros de composto orgânico, de mesma formulação utilizada na primeira adubação, nas parcelas referentes ao tratamento que seria implantado em cada um dos blocos, coletando-se, em seguida, amostras de solo para análise físico-química (Tabela 1).

Para a semeadura direta utilizou-se sementes de rabanete cultivar cometo pertencentes a um mesmo lote, com percentuais de $99 \%$ e $85 \%$ de pureza e germinação, respectivamente. As semeaduras ocorreram sempre entre as 16 e as 17 horas dos dias determinados. A dimensão de cada parcela foi de $1 \mathrm{~m}$ de largura por $1,5 \mathrm{~m}$ de comprimento, com o espaçamento de $0,2 \mathrm{~m}$ entre linhas de cultivo e $0,1 \mathrm{~m}$ entre plantas. 
Tabela 1. Análise físico-química das amostras de solo de cada tratamento: dia de 'raiz' $\left(\mathrm{AM}_{1}\right)$; 'folha' $\left(\mathrm{AM}_{2}\right)$; 'flor' $\left(\mathrm{AM}_{3}\right)$; e 'fruto' $\left(\mathrm{AM}_{4}\right)$. Fortaleza, CE, 2015.

\begin{tabular}{|c|c|c|c|c|c|c|c|c|}
\hline & $\mathrm{pH}$ & $P$ & $\mathrm{~K}$ & $\mathrm{Zn}$ & $\mathrm{Fe}$ & $\mathrm{Mn}$ & $\mathrm{Cu}$ & B \\
\hline Amostras & & \multicolumn{7}{|c|}{$\mathrm{mg} \mathrm{dm}{ }^{-3}$} \\
\hline AM1 & 6,9 & 261,7 & 140,0 & 61,6 & 16,1 & 53,7 & 0,9 & 0,4 \\
\hline AM2 & 6,7 & 254,3 & 127,0 & 61,2 & 15,5 & 45,6 & 0,8 & 0,5 \\
\hline AM3 & 7,0 & 261,7 & 140,0 & 65,5 & 16,6 & 67,8 & 1,0 & 0,6 \\
\hline \multirow[t]{3}{*}{ AM4 } & 6,8 & 247,2 & 114,0 & 55,2 & 11,6 & 40,7 & 0,8 & 0,5 \\
\hline & $\mathrm{Ca}$ & $\mathrm{Mg}$ & $\mathrm{Al}$ & $(\mathrm{H}+\mathrm{Al})$ & Areia & Silte & Argila & MO \\
\hline & \multicolumn{4}{|c|}{$\mathrm{cmol}_{\mathrm{c}} \mathrm{dm}^{-3}$} & & $\%$ & & $\mathrm{~g} \mathrm{~kg}^{-1}$ \\
\hline AM1 & 6,4 & 4,0 & 0,0 & 1,32 & 83,0 & 11,0 & 6,0 & 4,82 \\
\hline AM2 & 7,7 & 4,9 & 0,0 & 1,32 & 82,0 & 11,0 & 7,0 & 4,82 \\
\hline AM3 & 6,8 & 4,2 & 0,0 & 1,32 & 83,0 & 12,0 & 5,0 & 4,97 \\
\hline AM4 & 6,8 & 4,4 & 0,0 & 1,15 & 82,0 & 10,0 & 8,0 & 4,97 \\
\hline
\end{tabular}

Fonte: Laboratório de Análise de Solos Viçosa Ltda, 2015.

Aos 10 dias após a semeadura (DAS), realizou-se o desbaste das plântulas e a adubação de cobertura com 5 litros por metro linear do mesmo composto utilizado na adubação inicial; a adubação de cobertura foi repetida aos 25 DAS.

Aos 29 DAS realizou-se a medição das clorofilas ' $a$ ' e ' $b$ ' com um medidor eletrônico (Clorofilômetro), modelo CFL1030 Falker. Para a determinação destes resultados procedeuse a medição de 20 plantas por parcela, totalizando 100 plantas por tratamento.

Aos 31 DAS, entre 8 e 10 horas, realizaram-se as avaliações de trocas gasosas com o uso de um analisador de gás infravermelho (IRGA), modelo LCi ADC. Foram avaliadas a concentração interna de $\mathrm{CO}_{2}\left(\mathrm{C}_{\mathrm{i}}, \mathrm{ppm}\right)$; fotossíntese $\left(A, \mu \mathrm{mol} \mathrm{m} \mathrm{m}^{-2} \mathrm{~s}^{-1}\right)$; fotossíntese total (At, $\left.\mu \mathrm{mol} \mathrm{m}^{-2} \mathrm{~s}^{-1}\right)$, estimada a partir da aplicação de regra de três simples relativa à fotossíntese líquida, medida em $6,25 \mathrm{~cm}^{2}$ da folha com a área foliar total; e a eficiência instantânea de carboxilação $\left(A / C_{i}\right)$, obtida pela razão entre a fotossíntese $(A)$ e $\mathrm{C}_{\mathrm{i}}$. Na sequência, as plantas foram colhidas e encaminhadas ao laboratório para a determinação dos seguintes parâmetros: número de folhas (NF); massa fresca da parte aérea (MFPA, g); massa seca da parte aérea (MSPA, g), determinada a partir da secagem das folhas em estufa com circulação forçada de ar, a $60^{\circ} \mathrm{C}$, por $48 \mathrm{~h}$, até a obtenção de massa constante; área foliar $\left(\mathrm{AF}, \mathrm{cm}^{2}\right.$ ), determinada pelo medidor de área foliar modelo 3100 Área Meter LI-COR; percentual de plantas tuberizadas (PTUB, \%), obtido pelo número de plantas com túberas de diâmetro igual ou superior a $20 \mathrm{~mm}$ dividido pelo número total de plantas da parcela; percentual de túberas rachadas (PTR, \%), obtido pelo número de túberas rachadas dividido pelo número total de túberas; diâmetro (DT, $\mathrm{mm})$ e comprimento da túbera ( $\mathrm{CT}, \mathrm{mm})$, medido com um paquímetro digital; massa fresca da túbera (MFT, g); massa seca da túbera (MST, g), determinada a partir da secagem das túberas em estufa com circulação forçada de ar, a $60{ }^{\circ} \mathrm{C}$, por $48 \mathrm{~h}$, até a obtenção de massa constante; produção total (PT, $\mathrm{kg} \mathrm{ha}{ }^{-1}$ ),

Cultura Agronômica, Ilha Solteira, v.26, n.3, p.375-383, 2017 
considerando-se as raízes tuberizadas comercializáveis e rachadas. Para a determinação de todas as massas utilizou-se balança digital de precisão.

Os dados obtidos foram submetidos à análise de variância pelo teste $\mathrm{F}$, sendo empregado o teste de Scott-Knott para comparação entre as médias. Utilizou-se para o procedimento das análises a versão 5.6 do software Sisvar (FERREIRA, 2011).

\section{RESULTADOS E DISCUSSÃO}

Foram observadas diferenças significativas $(\mathrm{p} \leq 0,01)$ entre os tratamentos quanto às características número de folhas, massas fresca e seca das partes aérea e área foliar (Tabela 2). As maiores médias para estas características foram observadas nas plantas semeadas em 'dia de flor'. Para área foliar não foi observada diferença entre 'dia de flor' e 'dia de fruto', sendo ambas superiores aos demais tratamentos.

Tabela 2. Médias de número de folhas (NF), massas fresca (MFPA) seca da parte aérea (MSPA) e área foliar (AF) de plantas de rabanete. Fortaleza, CE, 2015.

\begin{tabular}{ccccc}
\hline Tratamento & NF & MFPA $(\mathrm{g})$ & MSPA $(\mathrm{g})$ & AF $\left(\mathrm{cm}^{2}\right)$ \\
\hline Dia de Raiz & $6,61 \mathrm{~b}^{*}$ & $12,38 \mathrm{~b}$ & $1,02 \mathrm{~b}$ & $309,82 \mathrm{~b}$ \\
Dia de Folha & $6,11 \mathrm{c}$ & $12,09 \mathrm{~b}$ & $1,04 \mathrm{~b}$ & $257,48 \mathrm{c}$ \\
Dia de Flor & $7,12 \mathrm{a}$ & $21,87 \mathrm{a}$ & $1,31 \mathrm{a}$ & $342,52 \mathrm{a}$ \\
Dia de Fruto & $5,92 \mathrm{c}$ & $13,80 \mathrm{~b}$ & $1,06 \mathrm{~b}$ & $336,17 \mathrm{a}$ \\
\hline CV $(\%)^{* *}$ & 19,94 & 41,72 & 44,06 & 33,35 \\
\hline
\end{tabular}

*Médias seguidas por letras iguais, na coluna, não diferem entre si ao nível de 5\% de significância, pelo teste Scott-Knott. ** Coeficiente de variação.

Schwengber et al. (2009) avaliaram diferentes épocas de semeadura (dia de raiz, folha, flor e fruto) para cultivares de cenoura e não constataram diferença entre os tratamentos quanto ao número e à massa seca das folhas, ao contrário do observado neste trabalho. No entanto, foi observada diferença quanto à massa fresca das folhas, sendo o 'dia de raiz' o tratamento com maior média, diferente do observado neste trabalho cujo tratamento com maior média foi o 'dia de flor'.

Para as características percentual de tuberização, percentual de túberas rachadas, diâmetro, comprimento, massas fresca e seca das túberas e produção total de túberas por hectare não foram observadas diferenças significativas (Tabela 3).

De forma semelhante ao observado neste trabalho, Schwengber et al. (2009) também não observaram diferenças para o comprimento e massa seca de cenoura. No entanto, verificaram diferença para o diâmetro e massa fresca da raiz, com maiores médias em 'dia de fruto' e 'de raiz', respectivamente. Além disso, Jovchelevich (2007) trabalhando com cenoura, Schwengber et al. (2013) com beterraba e Menin et al. (2014) com rabanete também não observaram diferenças nas características de crescimento das raízes das plantas independentemente de sua época de semeadura. 
Tabela 3. Percentual de tuberização (PTUB), percentual de túberas rachadas (PTR), diâmetro (DT) e comprimento de túberas (CT), massas fresca (MFT) e seca de túberas (MST) e produção total de túberas (PT) de rabanete. Fortaleza, CE, 2015.

\begin{tabular}{cccccccc}
\hline Tratamento & PTUB & PTR & DT & CT & MFT & MST & PT \\
\hline \multicolumn{7}{c}{$(\%)$} & \multicolumn{2}{c}{$(\mathrm{mm})$} & & $(\mathrm{g})$ & $\mathrm{kg} \mathrm{ha}^{-1}$ \\
\hline Dia de Raiz & 85,62 & 48,30 & 31,45 & 34,41 & 17,81 & 0,93 & $10.993,60$ \\
Dia de Folha & 81,17 & 47,75 & 30,75 & 36,10 & 19,04 & 1,03 & $10.534,18$ \\
Dia de Flor & 78,78 & 41,67 & 31,81 & 37,61 & 23,90 & 1,04 & $16.203,94$ \\
Dia de Fruto & 86,57 & 45,42 & 30,88 & 35,77 & 20,59 & 0,98 & $12.686,96$ \\
\hline C.V. $(\%)^{*}$ & 9,95 & 20,08 & 18,00 & 25,40 & 45,76 & 43,07 & 27,72 \\
\hline
\end{tabular}

*Coeficiente de variação.

Segundo Menin et al. (2014), o fato de não ter sido encontrado um dia ideal para a produção de raízes pode estar relacionado ao fato de todas as semeaduras terem sido realizadas durante uma mesma fase da Lua, neste caso a 'Crescente', o que permite inferir que diferenças significativas de produção possam estar mais relacionadas com períodos astronômicos mais distantes, por exemplo entre fases lunares, tendo em vista que cada uma dura aproximadamente uma semana.

Segundo Spiess (1994), citado por Jovchelevich (2007), a produtividade das plantas depende mais dos ritmos anomalístico (perigeu ou apogeu) e tropical (ascendente ou descendente) da Lua que dos dias específicos citados pelo calendário astronômico tidos como o período mais adequado para cada atividade em determinada fase lunar. Este fato leva a inferir que a produção de rabanete em uma mesma fase da Lua, ainda que em dias variados, não proporciona resultados significativamente diferentes.

Para as características clorofila ' $\mathrm{a}$ ' e ' $b$ ' foram observadas diferenças entre os tratamentos (Tabela 4). O maior valor de clorofila 'a' foi obtido nos dias 'de folha' e 'de flor', sendo ainda o 'dia de folha' o que proporcionou também maior teor de clorofila ' $b$ '.

Tabela 4. Médias de clorofila ' $a$ ' $\left(\mathrm{CL}_{a}\right)$, clorofila ' $b$ ' $\left(\mathrm{CL}_{\mathrm{b}}\right)$, concentração interna de $\mathrm{CO}_{2}$ $\left(\mathrm{C}_{\mathrm{i}}\right)$, fotossíntese líquida $(A)$, fotossíntese total $\left(A_{\mathrm{t}}\right)$ e eficiência instantânea de carboxilação $\left(A / C_{i}\right)$ de rabanete. Fortaleza, CE, 2015.

\begin{tabular}{ccccccc}
\hline Tratamentos & CLa & CLb & Ci & $A$ & $A \mathrm{t}$ & $A / \mathrm{Ci}$ \\
\hline Dia de Raiz & $22,50 \mathrm{~b}^{*}$ & $4,86 \mathrm{~b}$ & $298 \mathrm{c}$ & $23,24 \mathrm{a}$ & $7.074 \mathrm{a}$ & $0,078 \mathrm{a}$ \\
Dia de Folha & $23,66 \mathrm{a}$ & $5,30 \mathrm{a}$ & $324 \mathrm{a}$ & $19,46 \mathrm{~d}$ & $4.956 \mathrm{~b}$ & $0,061 \mathrm{~d}$ \\
Dia de Flor & $23,30 \mathrm{a}$ & $4,76 \mathrm{~b}$ & $304 \mathrm{~b}$ & $20,16 \mathrm{c}$ & $6.822 \mathrm{a}$ & $0,067 \mathrm{~b}$ \\
Dia de Fruto & $21,50 \mathrm{c}$ & $4,48 \mathrm{c}$ & $327 \mathrm{a}$ & $21,04 \mathrm{~b}$ & $7.123 \mathrm{a}$ & $0,064 \mathrm{c}$ \\
\hline C.V. $(\%)^{* *}$ & 8,64 & 17,04 & 2,51 & 9,02 & 34,94 & 10,82 \\
\hline
\end{tabular}

*Médias seguidas por letras iguais, na coluna, não diferem entre si ao nível de 5\% de significância, pelo teste Scott-Knott. **Coeficiente de variação.

As clorofilas são pigmentos naturais encontrados nos cloroplastos e têm a função de aumentar a eficiência tanto na captação da luz quanto na distribuição da energia produzida, Cultura Agronômica, Ilha Solteira, v.26, n.3, p.375-383, 2017 
aprimorando o processo fotossintético e funcionando como "complexo antena" (TAIZ; ZEIGER, 2013). Os principais tipos desses pigmentos são a clorofila ' $a$ ', presente nos eucariotos fotossintetizantes; e a clorofila ' $b$ ', presente nas plantas e em alguns tipos de algas (KERBAUY, 2012). Segundo Moraes et al. (2000), maiores teores de clorofila não necessariamente implicam na observância de maiores taxas fotossintéticas, o que de certa forma concorda com os resultados observados neste trabalho, pois as plantas semeadas em 'dia de folha' apresentaram maiores valores médios das clorofilas 'a' e 'b' e menores taxas de fotossíntese líquida, fotossíntese total e de eficiência de carboxilação.

Quanto aos parâmetros fisiológicos, diferenças entre os tratamentos foram observadas para todas as características (Tabela 4). Para a concentração interna de $\mathrm{CO}_{2}(\mathrm{Ci})$, as médias nas folhas de plantas semeadas em 'dia de folha' e 'de fruto' foram superiores às demais, sem diferirem entre si. Para a taxa fotossintética líquida, o dia de raiz foi estatisticamente superior a todos os outros. Quanto à taxa fotossintética líquida total $\left(A_{\mathrm{t}}\right)$, à exceção daquelas semeadas em 'dia de folha' que apresentaram as menores taxas $\left(4.956 \mu \mathrm{mol} \mathrm{m}^{-2} \mathrm{~s}^{-1}\right)$, todos os demais tratamentos não diferiram entre si, tendo produzido uma taxa média de aproximadamente $7.006 \mu \mathrm{mol} \mathrm{m} \mathrm{s}^{-2}$. Quanto à eficiência de carboxilação $(A / \mathrm{Ci})$, da mesma forma que o $A$, as plantas semeadas em 'dia de raiz' apresentaram maior eficiência $(0,078)$.

De forma geral, a carboxilação é considerada a etapa inicial do ciclo de CalvinBenson, que por sua vez é a forma mais importante de fixação do dióxido de carbono atmosférico e, consequentemente, de incorporação do carbono nas estruturas celulares, realizado na presença de luz e $\mathrm{CO}_{2}$ (TAIZ; ZEIGER, 2013). A eficiência instantânea de carboxilação $\left(A / C_{i}\right)$ funciona como um indicativo da eficiência fotossintética. Segundo Inouee e Ribeiro (1988), maiores eficiências fotossintéticas representam, em geral, maiores produções nos cultivos. Apesar do exposto, mesmo tendo sido observadas maiores taxas de eficiência carboxilativa no 'dia de raiz', não foi observado maior acúmulo de massa seca tanto nas partes aérea e subterrânea de plantas de rabanete.

\section{CONCLUSÃO}

Com base nos resultados obtidos para os parâmetros avaliados não foi possível comprovar a teoria geral proposta pela Astronomia Agrícola de que há um determinado dia capaz de proporcionar diferença significativa em termos de produção. Sendo a comprovação científica a respeito dessa linha de pesquisa ainda bastante limitada, faz-se necessária a elaboração de mais pesquisas com o objetivo de comprovar a real aplicabilidade de seus princípios, a fim de construir sua fundamentação teórica explicativa ou sua desmitificação.

\section{REFERÊNCIAS BIBLIOGRÁFICAS}

BEVILACQUA, H. E. C. R. Classificação das hortaliças. In: CASTANHEIRO, A. L. M.; BEVILACQUA, H. E. C. R.; SHIRAKI, J. N. (Coords.). Horta: cultivo de hortaliças. São 
Paulo: Prefeitura do Município de São Paulo, Secretaria Municipal do Verde e do Meio Ambiente, 2006. Disponível em: http://goo.gl/HpJnra. Acesso em: 31 mar. 2015.

FERREIRA, D. F. SISVAR: A Computer statistical analysis system. Ciencia e Agrotecnologia, Lavras, v. 35, n. 6, p.1039-1042, 2011.

GUIMARÃES, M. A.; E FEITOSA, F. C. Rabanete: condições ideais para o cultivo. Campo \& Negócios HF, Uberlândia, v. 8, n. 106, p.06-09, 2014.

INOUE, M. T.; RIBEIRO, F. A. Fotossíntese e transpiração de clones de Eucalyptus grandis e E. saligna. IPEF, Piracicaba, n. 40, p.15-20, 1988.

JOVCHELEVICH, P. Rendimento, qualidade e conservação pós-colheita de cenoura (Daucus carota L.), sob cultivo biodinâmico, em função dos ritmos lunares. 2007. 95f. Dissertação (Mestrado em Agronomia - Horticultura) - Faculdade de Ciências Agronômicas, Universidade Estadual Paulista, Botucatu, 2007.

KERBAUY, G. B. Fisiologia vegetal. 2. ed. Rio de Janeiro: Guanabara Koogan, 2012. 431 p.

LIRA, J. L. C. B. Produtividade, índice de equivalência de área e incidência de espontâneas em cultivo consorciado de alface. Brasília-DF: Universidade de Brasília "Faculdade de Agronomia e Medicina Veterinária", 2013. 31 p. (Trabalho de conclusão de curso)

MENIN, L. F.; RAMBO, J. R.; FRASSON, D. B.; PEREIRA, T. A. X.; E SANTI, A. Influência das fases lunares no desenvolvimento das culturas de rúcula (Eruca sativa Hill) e rabanete (Raphanus sativus L.). Revista Brasileira de Agroecologia, Porto Alegre, v. 9, n. 3, p.117-123, 2014.

MORAES, F. P.; E COLLA, L. M. Alimentos funcionais e nutracêuticos: definições, legislação e benefícios à saúde. Revista Eletrônica de Farmácia, Goiânia, v. 3, n. 2, p.109$122,2006$.

MORAES, R. M.; DELITTI, W. B. C.; MORAES. J. A. P. V. Respostas de indivíduos jovens de Tibouchina pulchra Cogn. à poluição aérea de Cubatão, SP: fotossíntese líquida, crescimento e química foliar. Revista brasileira de Botânica, São Paulo, v. 23, n. 4, p.443449, 2000.

ORMOND, J. G. P.; PAULA, S. R. L.; FAVERET FILHO, P. S. C.; E ROCHA, L. T. M. Agricultura orgânica: quando o passado é futuro, 2002. Disponível em: https://web.bndes.gov.br/bib/jspui/handle/1408/2479 . Acesso em: 23 de mar. 2015.

PEREIRA, E. R. Cultivo da rúcula e do rabanete sob túneis baixos cobertos com plásticos com diferentes níveis de perfuração. 2002. 113 f. Dissertação (Mestrado em Agronomia - Irrigação e Drenagem) - Escola Superior de Agricultura "Luís de Queiroz", Universidade de São Paulo, Piracicaba-SP, 2002.

Cultura Agronômica, Ilha Solteira, v.26, n.3, p.375-383, 2017 
SCHWENGBER, J. E.; CUSTODIO, T.; MALTZAHN, L. E.; MORAES, R. T.; ZANATTA, T.; E PEREIRA, C. V. Produção de beterrabas semeadas segundo o calendário astronômico agrícola. Cadernos de Agroecologia, Porto Alegre, v. 8, n. 2, p.2236-7934, 2013.

SCHWENGBER, J. E.; SCHIEDECK, G.; VIZZOTTO, M.; CAPELlESSO, A. J.; AUMONDE, T. Z.; SILVA, J. B.; MOREIRA, V.; PEREIRA, M. C. Produção orgânica e qualidade de cenouras qualidade de cenouras semeadas segundo o calendário astronômico agrícola. 1. ed. Pelotas: Embrapa Clima Temperado, 2009. 25 p. (Boletim técnico, 91).

SIXEL, B. T. Biodinâmica e Agricultura: amar a Terra, amar o Sol, um caminho para a agricultura no Brasil e para as regiões tropicais e subtropicais da Terra a partir da Antroposofia de Rudolf Steiner. 1. ed. Botucatu: Associação Brasileira de Agricultura Biodinâmica, 2003. 252 p.

TAIZ, L.; E ZEIGER, E. Fisiologia Vegetal. 5. ed. Porto Alegre: Artmed, 2013. 954 p.

THUN, M. O trabalho na terra e as constelações. Botucatu: Associação Brasileira de Agricultura Biodinâmica, 1986. 56 p.

THUN, M. Calendário Astronômico-Agrícola 2015. Botucatu: Associação Brasileira de Agricultura Biodinâmica, 2015. 198 p. 